University of Wollongong

Research Online

Faculty of Social Sciences - Papers (Archive) Faculty of Arts, Social Sciences \& Humanities

$1-1-2017$

Empowering Nonnative-English-Speaking Teachers in Primary School

Contexts: An Ethnographic Case Study

Michael S. Burri

University of Wollongong, mburri@uow.edu.au

Follow this and additional works at: https://ro.uow.edu.au/sspapers

Part of the Education Commons, and the Social and Behavioral Sciences Commons

Research Online is the open access institutional repository for the University of Wollongong. For further information contact the UOW Library: research-pubs@uow.edu.au 


\title{
Empowering Nonnative-English-Speaking Teachers in Primary School Contexts: An Ethnographic Case Study
}

\author{
Abstract \\ With the prospect of economic growth, governments in many parts of the world where English is spoken \\ as an additional language have pushed for educational reforms and introduced English at the primary \\ school level. However, the implementation of such reforms along with a general lack of training \\ opportunities available to primary school teachers has caused considerable uncertainty and anxiety \\ among practitioners. This article reports on a small-scale ethnographic case study that explored a \\ Japanese approach to English teaching/learning with the aim of identifying pedagogical practices that \\ nonnative-English-speaking teachers could implement in their primary English lessons. Seven \\ observations, four unstructured interviews, and five semistructured interviews were triangulated to collect \\ data in the Kansai and Tokyo areas over a period of 4 weeks. Findings show that the approach consists of \\ seven distinct stages that not only include a multitude of pedagogical practices but also provide a rich \\ learning environment. Findings further suggest that two practices could be of particular use in primary \\ school contexts: input-focused teaching and theme-based teaching.

\section{Disciplines} \\ Education | Social and Behavioral Sciences

\section{Publication Details} \\ Burri, M. (2018). Empowering Nonnative-English-Speaking Teachers in Primary School Contexts: An \\ Ethnographic Case Study. TESOL Journal, 9 (1), 185-202.
}




\section{Empowering NNESTs in Primary School Contexts: An Ethnographic Case Study}

With the prospect of economic growth, governments in many parts of the world where English is spoken as an additional language have pushed for educational reforms and introduced English at the primary school level. However, the implementation of such reforms along with a general lack of training opportunities available to primary school teachers has caused considerable uncertainty and anxiety among practitioners. This paper reports on a small-scale ethnographic case study that explored a Japanese approach to English teaching/learning with the aim of identifying pedagogical practices that nonnative English-speaking teachers could implement in their primary English lessons. Seven observations, four unstructured interviews, and five semi-structured interviews were triangulated to collect data in the Kansai and Tokyo areas over a period of four weeks. Findings showed that the approach consists of seven distinct stages that, not only include a multitude of pedagogical practices, but also provide a rich learning environment. Findings further suggested that two practices could be of particular use in primary school contexts: input-focused teaching and theme-based teaching.

\section{Introduction}

The development of "economic globalization" has led to the rapid spread of the English language throughout the world (Shintani, 2016, p. 12). With this prospect of economic growth, many governments have made substantial changes to their English education policies (see, for instance, Fang \& Garland, 2014, for recent curriculum reforms in China), including the introduction of English at the primary school level (e.g., Li, 2007). In the case of Japan - the context for this paper - the Ministry of Education, Culture, Sports, Science, and Technology (MEXT) announced an English Education Reform Plan in 2014. The plan requires that, from 2020 onwards, elementary ${ }^{1}$ school students will begin learning English to establish and "nurture the foundations for communication skills" (MEXT, 2014, n.p.) in grades three and four by conducting English language activities 1-2 times per week. In fifth and sixth grade, English will be a compulsory

\footnotetext{
${ }^{1}$ The terms 'primary' and 'elementary' are used interchangeably in this paper.
} 
subject, requiring teachers to use government approved textbooks in classes conducted three times a week to "nurture basic English language skills" (n.p.).

The Japanese example mirrors recent developments in most Asian countries in which English is spoken as a foreign language (see Spolsky \& Moon, 2012, for an excellent volume on English teaching in Asian primary schools). To achieve the goal of fostering students' communicative ability in English, policy makers in most Asian countries have promoted the use of communicative methods at primary school level (Butler, 2005). However, the implementation of such student-centered teaching has shown to be problematic in contexts in which more teacher-centered learning is traditionally used (Littlewood, 2013; McKay, 2002). Research has demonstrated that the lack of English teaching guidelines, as well as classroom/instructional, conceptual, and institutional/societal constraints can cause considerable uncertainty among teachers about what and how to instruct their students in English (Butler, 2011; Butler \& Iino, 2005; Honna \& Takeshita, 2005; Nguyen \& Nguyen, 2007; Nunan, 2003). Other research has shown that the proficiency of many non-native English-speaking teachers (NNESTs) is insufficient to provide rich English input needed to enhance their students' L2 learning (Butler, 2004). Consequently, many practitioners lack confidence and report feelings of insecurity and anxiety about teaching English to their pupils (Butler, 2007; Machida, 2016; Shintani, 2016) even though native-speaker proficiency may not be necessary for elementary school English teachers (Nunan, 2003). Additional issues include a shortage of pedagogical resources for many teachers of young learners, inconsistencies in the quality of government-approved textbooks, and limited systematic support and training provided to teach English in primary contexts (Butler, 2004; Li, 2007; Nguyen, 2011; Nguyen \& Nguyen, 2007; Nunan, 2003; Spolsky \& Moon, 2012). In light of these concerns, I set out to conduct a study that explored ways to assist primary school teachers with teaching English to their students. The objective was to research a popular, local teaching approach used by a group of NNESTs to increase the likelihood that findings would be relevant to other non-native teachers of young learners. Another reason for researching a local approach to second language (L2) teaching was the field's recent pedagogical shift towards acknowledging the powerful influence that local contexts exert on L2 teaching and learning (Canagarajah, 2005; Kumaravadivelu, 2006). Consideration of the local context - the learners, their culture, first language (L1), background knowledge, socio-economic status, as well as institutional factors and stakeholders - when teaching language has been coined 'context- 
sensitive pedagogy' (Littlewood, 2013). This form of L2 teaching is believed to enhance the learning of an additional language because the needs of local students are taken into account. Littlewood (2013) and Bax (2003) discuss context-sensitive pedagogical principles that instructors could adopt in their classrooms to facilitate L2 learning; yet, in spite of this recent paradigmatic shift, from an empirical perspective relatively little is known about what constitutes contextualized pedagogy. Moreover, judging the merits of contextualising L2 pedagogy seems to be problematic without first having an in-depth understanding of the context.

This current study, therefore, examined a local approach designed in Japan to facilitate Japanese students' learning of English. This type of research is expected to not only deepen our understanding of what effective local pedagogy entails, but also provide insights into useful practices for teaching English to primary children. For NNESTs who struggle with a lack of confidence or anxiety, these findings might be particularly beneficial. Given the general lack of training currently available to elementary school teachers, equipping teachers with relevant pedagogical tools and resources might support, and ultimately empower, NNESTs to teach English at the primary school level.

\section{A Local Approach to English Language Teaching in Japan}

The aim of this paper is to report on a small-scale ethnographic case study that explored an approach to foreign language learning developed by the Labo Teaching Information Center in Japan. It is important to note that the goal of the study was not to promote the institution, nor to evaluate the effectiveness of the approach or "to find a single best way of teaching" (Littlewood, 2013, p. 11). Such a goal would undermine the premise of context-sensitive pedagogy in which this research is situated. Rather, as discussed previously, my intention was to obtain some pedagogical insights, such as, for example, instructional techniques that may be of use to NNESTs teaching English to young learners. ${ }^{2}$ I hoped to establish a "pool [of pedagogical practices] on which teachers can draw in order to design classroom practices which are real and meaningful to their learners and help learners towards fulfilling their communicative needs" (Littlewood, 2013, p. 10).

Labo is a supplementary English program situated outside of Japanese mainstream education. The organization was established in 1962, and has currently 11 branches throughout

\footnotetext{
${ }^{2}$ Formal permission was obtained from Labo to conduct this research.
} 
Japan. Labo views foreign language learning as a fun and natural process for which in-house produced storybooks, songs, and dramas (featuring bilingual texts and audio recordings) are used (Acton, 1993; The World of Labo, 2016). These pedagogical aspects stimulated my interest in researching this approach, as it seemed to encompass several characteristics that could potentially be applied to primary school contexts. I was also intrigued by the fact that Labo was unique to Japan, and that, in spite of its apparent popularity (there are more than 2,000 classes or “parties" throughout Japan, totalling of over 20,000 members), only limited literature and research (Acton, 2001a, 1993) on this approach was available in English. Acton suggests that the heart of the organization is the Labo Party (henceforth party), typically taught by a female tutor (teacher) who invites children from the community to join her party. However, Acton's work does not provide a detailed account of what occurs during a party. Subsequently, I decided to obtain an emic (i.e., insider) perspective on the approach and explore whether certain pedagogical practices could indeed be of any use to NNESTs teaching English to children in the public primary school system. The following research questions guided this study:

1. What are the characteristics of a "Labo Party" and what pedagogical practices does a tutor use during her party?

2. Given the limited support and training that non-native primary teachers of English receive, which of these practices show the greatest potential to be used by NNESTs teaching English to primary school students?

\section{METHODOLOGY}

\section{Participants}

Labo arranged for me to visit three parties that were located in Osaka as I was based in that area during the data collection process. Labo chose the three participants or "tutors" (LT1 - LT3) due to their extensive involvement as tutors. Their experience ranged from 13 to 27 years, and their English proficiency level was intermediate. Besides learning English in junior and senior high school, LT1 spent two years in the USA, which enabled her to use English on a daily basis. Her party was taught in the northern part of Osaka and was made up of 15 children, aged five to 13. LT2 taught her party in the Kobe area. She also learned English in school and spent one month in Montana, USA, with Labo's student exchange program. She decided to become a tutor after 
noticing how much her daughters enjoyed being Labo students. Her party included five children, aged eight to 10. The party taught by LT3 was located in the west of Osaka. She explained that her decision of becoming a tutor was due to her appreciation for Labo combining English education with child development. Her party was attended by eight pupils, aged eight to 13 .

In addition to the three tutors, five Japanese teacher educators (TE1 - TE5) that were associated with Labo agreed to take part in the research project. Labo selected the TEs based on their availability and experience with training English teachers and Labo tutors. All five TEs were considered to be experts in English education and teacher training in Japan. It was, therefore, expected that the TEs were going to provide important information into the party system and primary school English; insights that would help answer the research questions. TE1 taught English at two private elementary schools in Tokyo and conducted short-term in-service

training for Japanese elementary school teachers of English. TE2 was a university professor, and a former curriculum specialist with MEXT; TE3 was a faculty member at a prestigious private university in Tokyo. TE4 was a professor at a prominent private university in Tokyo and was part of the foreign language committee of the central council of education, an advisory board to MEXT. Lastly, TE5 was an English teacher at a private elementary school and conducted workshops for English instructors in Tokyo.

\section{Data Collection and Analysis}

The study reflected ethnographic inquiry, in which classroom observations and two types of interviews were triangulated to collect qualitative data. A total of seven observations and four 30-minute, unstructured interviews were conducted with the three tutors over a period of three weeks (LT1 was interviewed twice to clarify some pedagogical aspects I had observed). In line with common ethnographic research practice, I chose a non-participatory approach for the party observations. This allowed me to not only focus on the various pedagogical practices occurring during a party, but to remain as inconspicuous as possible (Kanno \& Stuart, 2011). During each observation, key words were recorded, and a few hours later, away from the research site, the notes were expanded into descriptive (i.e., detailed) fieldnotes. Before returning to a party to begin the observation process anew, preliminary themes were coded in the expanded fieldnotes. This ethnographic research cycle (Spradley, 1980) enabled me to make some initial 
interpretations based on emerging themes and, at the same time, to begin to form an understanding of pedagogical practices tutors used in their parties.

The interviews with the tutors (all conducted in English) contained little structure because spontaneous questions based on observations were asked in order to elicit new information, clarify meaning, and obtain the tutors' perspective and perception of pedagogical practices. The interviews with the five teacher educators (also conducted in English) lasted approximately 4560 minutes. The sessions were held in Tokyo, one week after the tutors were observed and interviewed. These interviews were conducted with the objective of obtaining additional insights into the party system. A semi-structured approach was used as this provided me with flexibility to probe and ask for clarification in regards to the focus of the study. That is, a few questions were prepared ahead of the interviews to ensure that I was able to ask spontaneous questions as well.

All of the interviews with the LTs and TEs were recorded with an Olympus digital voice recorder and transcribed verbatim upon completion of the data collection. Observation and interview data were coded thematically, and a combination of letters was chosen for each code marking a theme. As such, letters were arranged in a way that "[kept] them semantically close to the themes they represent[ed]" (Ellis \& Barkhuizen, 2005, p. 267). The codes were then examined for similarities and clustered into categories (Holliday, 2015). Creating separate categories allowed me to better identify specific patterns in the data. Following the analysis, a colleague and experienced ethnographer was consulted to scan the coding and categorization of the data to ensure inter-rater reliability.

It is important to note that I am a NNEST myself and had taught English in Japan for a few years prior to this study. Thus, my language learning background, and, particularly, the experience gained from living in Japan was likely to allow me to approach the study with an emic perspective on the Japanese culture, language, and traditions, which, in turn, was expected to assist with objectivity towards the local pedagogy under investigation.

\section{FINDINGS AND DISCUSSION}

In the first half of the discussion, a detailed (i.e., emic) description of the party is provided to answer the first research question. In the subsequent half, pedagogical practices relevant to 
NNESTs teaching English to primary-aged children are discussed to answer the second research question.

\section{The Party}

A party is normally held once a week, after the conclusion of mainstream schooling in the afternoon. Children residing in the local community are welcome to join. As Figure 1 depicts, a typical party consists of seven distinct stages, lasting anywhere between 80 and 120 minutes. It follows a similar and predictable routine that supports the learners to relax and absorb language. Almost everything is connected to a central story (hence the dotted circle around the seven stages in Figure 1), and a variety of transition techniques, such as asking the children to form a circle, clapping, or chanting in Japanese, are used to move from one stage to the next.

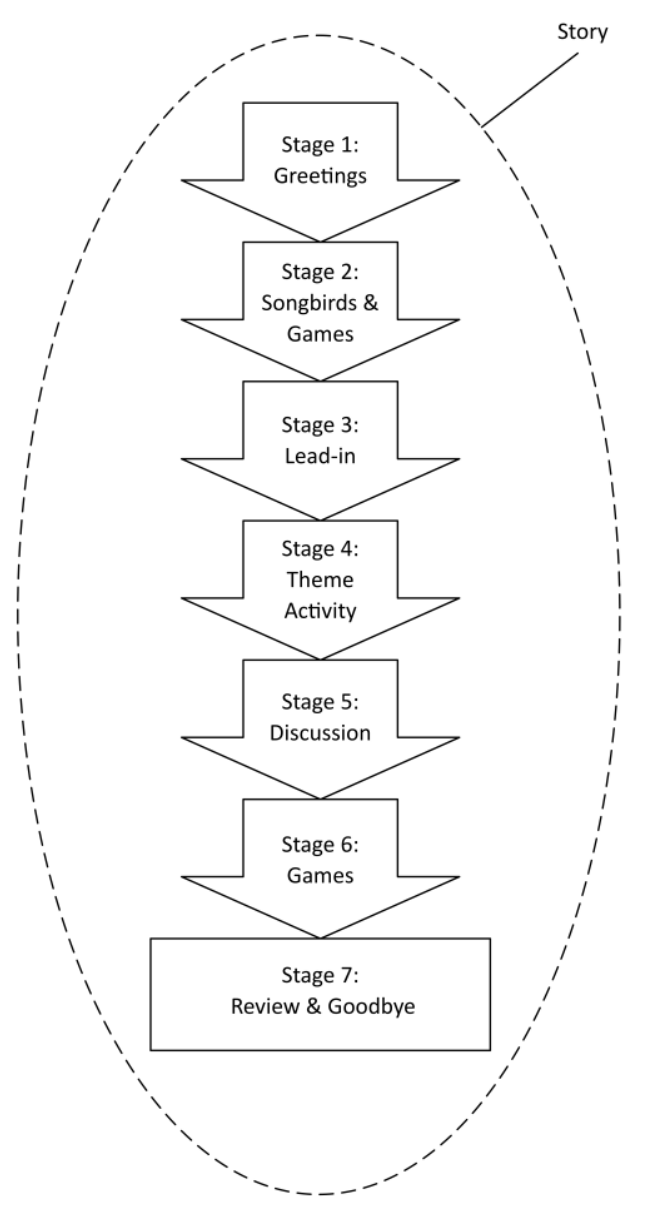

Figure 1. Seven stages of a party 
As the observation data showed, Japanese is predominantly used throughout a party. English input the children receive derives mostly from songs and stories that the tutor selects from the Labo library (it contains more 100 bilingual stories and about 300 songs). The seven stages of a party are:

Stage 1: The tutor greets the students and mothers, and collects the children's notebooks. The tutor may distribute a newsletter to inform the parents of any interesting party-related news.

Stage 2: After the initial greetings, the tutor suggests some 'Songbirds' (i.e., nursery rhymes, folksongs, and poems) and games, but, ultimately, the learners "choose what they want [to do]" (LT3). The tutor facilitates this process by asking the students (in Japanese) what game, for example, they would like to play. The tutors explained, giving the students a voice contributes to their development, and it allows them to enjoy the party more thoroughly. If a new song is introduced, the tutor talks with the students about it (in Japanese), while drawings, pictures and key words (often written in Japanese and/or English on a whiteboard) usually facilitate the learning of the song. Additionally, the tutor tends to model words and movements before any singing or playing takes place. Audio recordings are often used to aid the singing. As was observed, this stage can last from five to forty minutes depending on how the children feel at the beginning of the party. According to the tutors, if the children appear to be tired at the beginning, this stage is extended to help the students gradually disconnect from the stress experienced outside the party, and it prepares them for the following stages.

Stage 3: Leading the learners into the story lies at the core of the third phase and is accomplished in two ways. First, a discussion - usually stimulated with pictures and photos about the content of the story takes place (in Japanese), or the tutor reads out parts of the story (in Japanese), asks the students to recreate the narrative (in Japanese), or recites and repeats some English poems with the group. Alternatively, the tutor might present key 'kanji' (i.e., Chinese characters) appearing in the text to further discuss content-related matters and the meaning of these Chinese characters. During the discussion, the tutor frequently asks which story characters the children would like to represent, and which motions they thought could accompany these roles. The tutor also models movements and some of the English and Japanese language occurring in the story as a means to enhance the students' understanding of it. If uncertainty or misunderstandings exist, or if learners opt for unrealistic roles, the tutor suggests some different roles and moves, but, generally, the children take the initiative and choose, 
allowing them to stay interested and to draw from their "rich imagination" (LT1, Interview 2). An average of 20 minutes is spent on this stage before the students position themselves in the classroom according to the characters they have chosen. If the number of roles in a story is limited, several children form a group signifying one character.

Stage 4: The tutors pointed out that this part is called the 'Theme Activity.' The students and the tutor act the story out together, frequently shadowing (i.e., echoing) the English and Japanese narration played off a CD (a story is usually narrated on a paragraph by paragraph basis with English preceding Japanese). When a new story is introduced, the tutor fully participates in the theme activity to gain insights into the students" "feelings and ideas" (LT2), but over the span of a few weeks, she gradually withdraws from the group to minimize the possibility of her being the center of attention. Unless the focus is on accurately performing and comprehending key sequences in the story, the tutor does not interrupt the theme activity. The theme activity generally takes thirty to thirty-five minutes to complete, and about four weeks are spent on one story.

Stage 5: Following the theme activity, sitting in a circle with the children, the tutor talks with the pupils (in Japanese) about feelings, emotions, and images they formed during the fourth stage. The tutors suggested that this process bridges the gap that initially exists between a story and the students' understanding of it. In general, older students are expected to lead the discussion and assist younger learners in expressing themselves. The group often writes English and/or Japanese words associated with feelings, emotions, and images on a large piece of paper, while some students may show their notebooks containing writings and drawings about the story to the rest of the class. The word list is expanded weekly to facilitate learning and understanding of the story. Depending on the party, this fifth stage takes anywhere between five to twenty-five minutes.

Stage 6: The learners are provided with an opportunity to relax and produce English without having to consciously pay attention to the process. A simple game, typically linked back to the content and characters occurring in the theme activity, is played for five to 10 minutes. The game usually includes the recitation of an English rhyme, or the formation of basic questions and answers, along with some form of intensive movement, such as a competition between two individuals or teams. 
Stage 7: In this last stage, the tutor briefly reviews some of the content covered during a party, and then encourages the children to spend time at home listening to the bilingual recording and to write and draw in their notebooks. Before the children leave, the group sings a goodbye song together, and snacks are always shared at the end of a party.

\section{Pedagogical Practices Relevant to NNESTs Teaching English at Primary Schools}

As the above overview showed, a party entails a rich learning environment in which a multitude of pedagogical practices are utilized. Arguably, a party with its seven stages is too comprehensive for primary teachers to incorporate in their classrooms; nonetheless, according to the three LTs and the five TEs, a party comprises two promising pedagogical practices which could be used by primary school NNESTs: input-focused teaching and theme-based teaching.

Input-focused teaching. For teaching contexts with limited number of hours dedicated to English learning, all five TEs viewed input-focused teaching to be of value to primary school teachers. TE3 and TE5, for instance, both believed that teachers could supplement their classes with some of the storybooks and audio materials the tutors frequently use. TE3 suggested that teachers devote the first 10 minutes of each day to having the children enjoy and listen to stories without focusing on $\mathrm{L} 2$ production. The bilingual nature of these stories may be particularly suitable for young learners, as they get exposure to the meaning of a story in both languages. This may not only facilitate the pupils' understanding of a story's meaning but also enhance memorization (Acton, 2001a) and, therefore, increase L2 learning opportunities (Littlewood, 2013).

Listening to stories could also be assigned as homework. As the tutors explained, students are encouraged to listen to recordings of a story at home to increase their understanding and imagination. ${ }^{3}$ The tutors added that because the children listen to a narration many times outside a party (sometimes more than 100 times), the learners begin to form mental images of the story, while improving their listening comprehension at the same time. Yet, it is reasonable to assume that some elementary schools might be reluctant to purchase additional resources due to funding-related issues, and given the many extra-curricular activities in which primary school

\footnotetext{
${ }^{3}$ On a more practical note, listening to recordings is important to the flow of a party. As was observed, if students do not listen to a story at home, they struggle with understanding the content of the story, and, subsequently, with acting it out.
} 
students are typically involved, listening to these stories numerous times at home might not be a realistic proposition.

Nonetheless, input-focused teaching is a promising characteristic of the party. NNESTs feeling insecure and anxious about their ability to teach English to young learners (Machida, 2016; Shintani, 2016) could utilize storybooks and audio recordings in their classrooms. Using an input focused approach would likely reduce the pressure of having to produce spoken language many NNESTs typically face when it comes to teaching English (Butler, 2007; Hiramatsu, 2005). As was discussed previously, finding ways to support primary school NNESTs is urgently needed. As such, the provision of language input through storybooks and audio recordings, as was done by the tutors in this study, could be an empowering practice for NNESTs teaching in primary school contexts.

Theme-based teaching. Another interesting pedagogical principle is the tutors' use of stories. The tutors explained that they value stories because they align with a theme-based approach to L2 teaching and learning. Also, TE1 considered a theme-based approach to be suitable for teaching English to young learners because it allows practitioners to create thematic units and include activities, tasks, and songs to increase children's interest in themes. TE1 suggested that raising primary-aged children's interest in particular topics was more effective than focusing purely on the attainment of L2 competency-related goals. In the literature, stories are regarded as an effective means to foster the development of positive attitudes towards a foreign language and culture, raise learner awareness of rhythm and intonation, facilitate emotions and imaginative skills and increase personal involvement because of students' identification with characters (e.g., Brewster, G. Ellis \& Girard, 2002; Wright, 2004).

It must be noted, however, that theme-based teaching can be extremely demanding for teachers in terms of planning and implementation (Cameron, 2001). Teachers must be flexible and sensitive to the language they teach or else their lessons may turn out to be chaotic (Dragan, 2005). As was observed, the tutors made frequent use of Japanese during a party. Being able to utilize the learners' L1 was critical in order to maintain control, manage classroom activities and explain meaning effectively (Cameron, 2001). Thus, employing theme-based teaching may not be practical for elementary school teachers unless they share the same L1 with their students, or are, at least, able to communicate proficiently in the students' mother tongue. The observations also allowed me to get a sense of how the tutors skillfully varied the pace during a party to 
ensure that the students were engaged at all times. Sometimes a tutor would stop an activity and sit with the learners in a circle if she felt the students did not understand some of the newly learned English vocabulary or needed to discuss the meaning of a particular section of a story. Accommodating students' needs to this extent is likely beyond the time frame that is available to elementary school teachers teaching English in their classrooms.

These challenges put the usefulness of a theme-based approach into question for English teachers at elementary schools. The lack of training generally available to primary school NNESTs (Butler, 2004; Li, 2007; Nguyen, 2011; Nunan, 2003; Spolsky \& Moon, 2012) also casts doubt on the usefulness of theme-based teaching. Thus, if theme-based teaching is to be used by primary school teachers, specific training needs to be made available so they are able to implement this pedagogical principle in their classrooms. ${ }^{4}$ Such training could be particularly worthwhile, since local teachers are in a favorable position to design appropriate thematic lessons based on their knowledge of the local context and students (Seidlhofer, 1999; Snow, Kamhi-Stein \& Brinton, 2006). Hence, even though the application of theme-based teaching may be challenging for L2 instructors, if proper training is provided, thematic teaching could be empowering to NNESTs teaching at primary school level. Given the notion of context-sensitive pedagogy meeting local students' needs (Bax, 2003; Littlewood, 2013), it is also reasonable to assume that thematic-lessons would likely be an effective facilitator of primary-aged children's L2 learning process because the content would be relevant to them.

\section{CONCLUDING REMARKS}

This study explored a popular approach of teaching English to young learners outside mainstream schooling in Japan. The findings may provide NNESTs in primary school contexts with practices they could implement in their classrooms. The extent the identified practices are context-sensitive and meet local students' L2 learning needs (Littlewood, 2013) is subject to further investigation; yet, it is hoped that the findings offer some encouragement, and, subsequently, reduce the anxiety of NNESTs teaching English to primary school children. It is quite possible, however, that a study designed and conducted by a Japanese researcher might have revealed a somewhat more emic perspective (Denzin \& Lincoln, 2011; Ellis \& Barkhuizen,

\footnotetext{
${ }^{4}$ Labo tutors are required to complete a 10-week training program before they are able to invite children to join their party (The World of Labo n.d.).
} 
2005). All of the interviews were conducted in English, and although the LTs and TEs possessed at least an intermediate proficiency level of English, the question of whether conducting the interviews in Japanese might have provided richer and perhaps slightly different data is a legitimate one. Nonetheless, I believe the study has generated some valuable findings and has subsequently created a platform for future research. The extent to which primary school NNESTs are able to implement the discussed practices should, for instance, be explored. This would almost certainly yield additional pedagogical insights that could further empower NNESTs in their challenging quest to teach English in their primary classrooms.

\section{ACKNOWLEDGMENTS}

I would like to express my gratitude to Labo for organizing the party observations and the interviews with the Labo associates. I would also like to thank the two reviewers, as well as Amanda Baker, Bill Acton, Winnie Pang, and Sam Lee for their insightful comments on earlier versions of this article.

\section{THE AUTHOR}

Michael Burri is a lecturer in TESOL at the University of Wollongong in Australia. He has taught and conducted research in Australia, Japan and Canada. His research interests include pronunciation teaching, second language teacher education, context-sensitive pedagogy and NNEST issues.

\section{REFERENCES}

Acton, W. (2001a). English poems and labo party. [Transcribed interview] LABO Teaching Information Center Chubu Branch, Japan.

Acton, W. (2001b). Focalspeak: Integrating rhythm and stress in speech-pronunciation. In J. Murphy \& P. Byrd (Eds.), Understanding the courses we teach: Local perspectives on English language teaching, (pp. 197-217). Michigan: The University of Michigan Press.

Acton, W. (1993). Marching to a different drama: Labo in the university ESL classroom. Bulletin of the Faculty of Commerce, Nagoya University of Commerce and Business Administration, 37(2), 245-267.

Bax, S. (2003). The end of CLT: A context approach to language teaching. ELT Journal, 57(3), 27-287. doi: 10.1093/elt/57.3.278

Brewster, J., Ellis, G., \& Girard, D. (2002). The primary English teacher's guide (2 ${ }^{\text {nd }}$ ed.). Essex: Pearson Education Limited. 
Brown, D. H. (2014). Principles of language learning and teaching $\left(6^{\text {th }}\right.$ ed.). White Plains: Pearson Longman.

Butler, Y. G. (2011). The implementation of communicative and task-based language teaching in the Asia-Pacific region. Annual Review of Applied Linguistics, 31, 36-57. doi: 10.1017/S0267190511000122

Butler, Y. G. (2007). Factors associated with the notion that native speakers are the ideal language teachers: An examination of elementary school teachers in Japan. JALT Journal, 29(1), 7-40.

Butler, Y. G. (2005). Comparative perspectives towards communicative activities among elementary school teachers in South Korea, Japan and Taiwan. Language Teaching Research, 9(4), 423-446. doi: 10.1191/13621688051r176oa

Butler, Y. G. (2004). What level of English proficiency do elementary school teachers need to attain to teach EFL? Case studies from Korea, Taiwan, and Japan. TESOL Quarterly, 38(2), 245-278. doi: 10.2307/3588380

Butler, Y. G., \& Iino, M. (2005). Current Japanese reforms in English language education: The 2003 “action plan". Language Policy 4(1), 25-45. doi: 10.1007/s10993-004-6563-5

Cameron, L. (2001) Teaching languages to young learners. Cambridge: Cambridge University Press.

Canagarajah, S. A. (Ed.). (2005). Reclaiming the local in language policy and practice. Mahwah: Lawrence Erlbaum.

Denzin, N. K., \& Lincoln, Y. S. (Eds.). (2011). The sage handbook of qualitative research (4th ed.). Thousand Oaks: Sage.

Dragan, P. B. (2005). A how-to guide for teaching English language learners in the primary classroom. Portsmouth: Heinemann.

Ellis, R., \& Barkhuizen, G. (2005). Analysing learner language. Oxford: Oxford University Press.

Fang, X., \& Garland, P. (2014). Teacher orientations to ELT curriculum reform: An ethnographic study in a Chinese secondary school. Asia-Pacific Education Researcher, 23(2), 311-319. doi: 10.1007/s40299-013-0106-9

Hiramatsu, S. (2005). Context and policy reform: A case study of EFL teaching in a high school in Japan. In D. Tedick (Ed.), Second language teacher education: International perspectives, (pp. 113-134). Mahwah: Lawrence Erlbaum.

Holliday, A. (2015). Qualitative research and analysis. In B. Paltridge \& A. Phakiti (Eds.), Research methods in applied linguistics: A practical course (pp. 49-62). New York: Bloomsbury.

Honna, N., \& Takeshita, Y. (2005). English language teaching in Japan: Policy plans and their implementations. RELC Journal, 36(3), 363-383. doi: 10.1177/ 0033688205060055

Kanno, Y., \& Stuart, C. (2011). Learning to become a second language teacher: Identities-inpractice. The Modern Language Journal, 95(2), 236-252. doi: 10.1111/j.15404781.2011.01178.x

Kumaravadivelu, B. (2006). Understanding language teaching: From method to postmethod. Mahwah: Lawrence Erlbaum.

Li, M. (2007). Foreign language education in primary schools in the People's Republic of China. Current Issues in Language Planning, 8(2), 148-160. doi: 10.2167/cilp113.0

Littlewood, W. (2013). Developing a context-sensitive pedagogy for communication-oriented language teaching. English Teaching, 68(3), 3-25. doi: 10.15858/engtea.68.3.201309.3 
Machida, T. (2016), Japanese Elementary school teachers and English language anxiety. TESOL Journal, 7(1), 40-66. doi: 10.1002/tesj.189

McKay, S. L. (2002). Teaching English as an international language. Oxford: Oxford University Press.

Ministry of Education, Culture, Sports, Science, and Technology. (2014). English education reform plan corresponding to globalization. Retrieved June 12, 2015 from http://www.mext.go.jp/english/topics/1343591.htm.

Nguyen, H. T. M. (2011). Primary English language education policy in Vietnam: Insights from implementation. Current Issues in Language Planning, 12(2), 225-249. doi: 10.1080/14664208.2011.597048

Nguyen, H. T. M., \& Nguyen, Q. T. (2007). Teaching English in primary schools in Vietnam: An overview. Current Issues in Language Planning, 8(2), 162-173. doi: 10.2167/cilp106.0

Nunan, D. (2003). The impact of English as a global language on education policies and practices in the Asia-Pacific region. TESOL Quarterly, 37(4), 589-613. doi: $10.2307 / 3588214$

Shintani, N. (2016). Input-based tasks in foreign language instruction for young learners. Philadelphia: John Benjamins Publishing Company.

Scovel, T. (2001). Learning new languages: A guide to second language acquisition. Boston: Heinle \& Heinle.

Seidlhofer, B. (1999). Double standards: Teacher education in the expanding circle. World Englishes, 18(2), 233-245. doi: 10.1111/1467-971X.00136

Snow, M. A., Kamhi-Stein, L. D., \& Brinton, D. M. (2006). Teacher training for English as a lingua franca. Annual Review of Applied Linguistics, 26, 261-281. doi: $10.1017 / \mathrm{S} 0267190506000134$

Spolsky, B., \& Moon, Y. (Eds.). (2012). Primary school English-language education in Asia. New York: Routledge.

Spradley, J. P. (1980). Participant observation. New York: Holt, Rinehart and Winston.

Stevick, Earl. (1978). Toward a practical philosophy of pronunciation: Another view. TESOL Quarterly, 12(2), 20-25.

The world of labo. (2016). Retrieved May 24, 2016 from http://labo-exchange.com/.

Wright, A. (2004). Storytelling with children. Oxford: Oxford University Press. 